\title{
Morphological Study of Hydrophilic-Hydrophobic Polymer System by Inverse Gas Chromatography: Physical Blends of Poly(ethylene oxide) with Polystyrene
}

\author{
Toshimitsu SuzUKI, Yoshimasa Murakami, Tomoyuki INUI, \\ and Yoshinobu TAKEGAMI \\ Department of Hydrocarbon Chemistry, Faculty of Engineering, \\ Kyoto University, Kyoto 606, Japan.
}

(Received April 28, 1981)

\begin{abstract}
The polymer-surface structure of a physical blend of poly(ethylene oxide) (PEO) with polystyrene (PS) was investigated by inverse gas chromatography and scanning electron microscopy. Phase separation occurred at a composition higher than ca. $30 \mathrm{wt} \% \mathrm{PEO}$. The PEO domain formed the island phase from ca. 30 to $44 \mathrm{wt} \%$ PEO. From 44 to $50 \mathrm{wt} \%$ PEO, the morphology of the polymer surface changed greatly: the PEO and PS domains formed the island and sea phases, respectively. In addition to these main domains, a smaller PS domain existed in the PEO domain; furthermore, the inversion of the sea-island phase took place around $50 \mathrm{wt} \% \mathrm{PEO}$. At loadings higher than $50 \mathrm{wt} \%$ PEO, the PEO domain formed the sea phase. The surface of the PS domain always protruded above the PEO domain regardless of the composition. At loadings lower than $c a .20 \mathrm{wt} \%$ PEO, the PEO domain was completely covered by the PS domain. These morphological changes in the polymer surface were perhaps due to the difference in the relative intensity of surface tension between PEO and PS. It was also found that poly(ethylene glycol) mono$p$-nonylphenyl ether acts as a surfactant in this polymer blend system.
\end{abstract}

KEY WORDS Inverse Gas Chromatography / Scanning Electron Microscopy / Polymer Blend / Poly(ethylene oxide) / Polystyrene / Morphology / Phase Separation / Surfactant /

Inverse gas chromatography (IGC) has been investigated by Guillet and his co-workers. ${ }^{1-4}$ IGC can be utilized to determine the glass transition temperature $\left(T_{\mathrm{g}}\right)$ or melting temperature $\left(T_{\mathrm{m}}\right)$ of a polymer. Information on polymer-solution thermodynamics and the degree of crystallinity can also be derived by IGC. ${ }^{5)}$ In recent years, IGC has been used to characterize block or random copolymers and discuss the morphology of microphase separation. ${ }^{6-9}$ More recently, DiPaola-Baranyi carried out a thermodynamic characterization of polymer blends of polystyrene (PS) with poly(n-butyl methacrylate) by IGC. ${ }^{10}$

Since poly(ethylene oxide) (PEO) and PS are highly imcompatible, phase separation occurs easily. Many attempts have been made to elucidate the morphology and physical properties of physical blends or block copolymers of PEO and PS. ${ }^{14-21}$ O'Malley et al. studied the surface topography of
PEO-PS polymer systems by X-ray photoelectron spectroscopy and proposed a new model for these systems. ${ }^{19-21}$ As a first step in the study of the morphology of amphiphilic block copolymers such as PEO- $b$-poly (methyl methacrylate) ${ }^{11-13}$ by IGC, $w^{22}$ clarified the important factors involved in preparing columns for obtaining a clearer $Z$-shaped diagram which is a distinctive featue of IGC.

In this study we used IGC and a scanning electron microscope (SEM) to investigate the polymer surface structure of physical blends of PEO with PS. This paper discusses the influence of composition on the polymer surface phase structure.

\section{EXPERIMENTAL}

\section{Materials}

Nakarai Chemical's PEO \#6000 $\left(M_{n}=4600\right)$ was 
used as received. Wako Pure Chemical's PS $\left(M_{n}=\right.$ 18000 ) was purified by dissolving in benzene and precipitating into methanol. Both PEO and PS were freeze-dried from a benzene solution under vacuum and stored. In our previous study on the columns of poly(methyl methacrylate) loaded Chromosorb, a clear Z-shaped retention diagram around the $T_{\mathrm{g}}$ was observed by using silane-treated Chromosorb. ${ }^{22}$ Therefore, in this study, Chromosorb P AW-DMCS (60-80 mesh, Gasukuro Kogyo) was also used as a support for the polymer. $n$-Octane was used as a "molecular probe," since its retention time could be measured in the column temperature range from 45 to $150^{\circ} \mathrm{C}$. Chloroform, a good solvent for PEO and PS, was employed to deposit polymer mixtures on Chromosorb. Tokyo Kasei's poly(ethylene glycol)mono- $p$-nonylphenyl ether [ $\mathrm{HO}\left(-\mathrm{CH}_{2} \mathrm{CH}_{2} \mathrm{O}\right)_{20} \mathrm{C}_{6} \mathrm{H}_{4} \mathrm{C}_{9} \mathrm{H}_{19}$, PEGNPE] was used as received. Trimethylchlorosilane and hexamethyldisilazane were used for silane-treatment of the glass plate surface on which polymer films were cast from the chloroform solution for SEM observation.

\section{Columns}

The columns prepared in this series of experiments are summarized in Table I. A certain amount of a PEO and PS mixture was dissolved in chloroform $(2.5 \mathrm{w} / \mathrm{v} \%)$ to which a certain amount of Chromosorb was added. In the case of column No. $17,0.4 \mathrm{wt} \%$ of PEGNPE $(20 \mathrm{mmol})$ was added to the polymer solution. The chloroform was allowed to evaporate at an ambient temperature by gentle and continuous stirring of the solution followed by drying at $45^{\circ} \mathrm{C}$ under slightly reduced pressure. The polymer loading $(\mathrm{wt} \%$ ) was calculated from the

Table I. Gas chromatographic columns ${ }^{\mathrm{a}}$

\begin{tabular}{|c|c|c|c|c|}
\hline \multirow{2}{*}{$\begin{array}{c}\text { Column } \\
\text { No. }\end{array}$} & \multicolumn{2}{|c|}{ PEO } & \multirow{2}{*}{$\frac{\text { Polymer loading }^{\mathrm{d}}}{\mathrm{wt} \%}$} & \multirow{2}{*}{$\frac{w_{\mathrm{PEO}}{ }^{\mathrm{c}}}{\mathrm{g}}$} \\
\hline & $\mathrm{wt} \% \mathbf{b}$ & $\mathrm{mol} \%{ }^{\mathrm{c}}$ & & \\
\hline 1 & 0 & 0 & 9.4 & 0 \\
\hline 2 & 10 & 21 & 9.6 & 0.047 \\
\hline 3 & 20 & 37 & 9.5 & 0.092 \\
\hline 4 & 25 & 44 & 9.5 & 0.112 \\
\hline 5 & 33 & 54 & 9.5 & 0.155 \\
\hline 6 & 39 & 60 & 9.6 & 0.185 \\
\hline 7 & 44 & 65 & 9.5 & 0.204 \\
\hline 8 & 47 & 68 & 9.7 & 0.220 \\
\hline 9 & 50 & 70 & 9.2 & 0.210 \\
\hline 10 & 80 & 90 & 10.0 & 0.397 \\
\hline 11 & 33 & 54 & 13.2 & 0.230 \\
\hline $12^{\mathrm{f}}$ & 0 & 0 & 0 & 0 \\
\hline 13 & 100 & 100 & 1.0 & 0.046 \\
\hline 14 & 100 & 100 & 5.0 & 0.225 \\
\hline 15 & 100 & 100 & 10.0 & 0.493 \\
\hline 16 & 100 & 100 & 20.0 & 1.028 \\
\hline $17^{g}$ & 52 & 72 & 9.5 & 0.257 \\
\hline $18^{\mathrm{h}}$ & 52 & 72 & 9.6 & 0.247 \\
\hline $19^{\mathrm{i}}$ & 50 & 70 & 9.7 & 0.228 \\
\hline
\end{tabular}

a Support: Chromosorb P AW-DMCS 60-80 mesh.

b $\mathrm{PEO}(\mathrm{g}) /[\mathrm{PEO}(\mathrm{g})+\mathrm{PS}(\mathrm{g})] \times 100$.

c Calculated by each monomer units.

d Calculated by the weight of whole polymer loaded.

e The weight of PEO fraction in a column.

f Only Chromosorb was packed in a column.

g Overlayer-loading (PS: upper layer).

${ }^{\text {h }}$ Overlayer-loading (PEO: upper layer).

i $\mathrm{PEGPhC}_{9} \mathrm{H}_{19}$ was added. 
weight increase in Chromosorb. A weighed amount of the polymer loaded Chromosorb was tightly packed into a $1.5 \mathrm{~m} \times 3 \mathrm{~mm}$ i.d. stainless steel column with a mechanical vibrator. The weight of the polymer deposited on the Chromosorb in the column $(w)$ was calculated from the polymer loading and the weight of the support packed into the column. The column was dried for $5 \mathrm{~h}$ at $45^{\circ} \mathrm{C}$ under a constant stream of helium. Several reference columns were also prepared (No. 1 and No. 12-16). Column No. 17 was an overlayer-loading model for PS/PEO. PEO was deposited on the Chromosorb from the chloroform solution followed by the loading of PS from the cyclohexane solution. Column No. 18 was also an overlayer-loading model for PEO/PS. PS was loaded onto the Chromosorb from the chloroform solution followed by the loading of PEO from the methanol solution.

\section{Gas Chromatography}

Gas chromatograms were recorded on a Yanaco G1800 equipped with a thermal conductivity detector, using helium as the carrier gas and air as a noninteracting marker. In all measurements the flow rate and the injection temperature were fixed at $10 \mathrm{ml} / \mathrm{min}$ and $100^{\circ} \mathrm{C}$, respectively. $n$-Octane $(0.6 \mu \mathrm{l})$ and air $(0.4 \mu \mathrm{l})$ were injected simultaneously. The net retention time $t_{\mathrm{R}}(\mathrm{min})$ from the air peak to the front side of the solute peak was measured. It has been already reported that the retention volumes on the front side of the solute peaks are independent of the injection size. ${ }^{23}$ The $t_{\mathrm{R}}$ is defined in terms of the specific retention volume $V_{\mathrm{g}}\left(\mathrm{ml} \mathrm{g}^{-1}\right)$ by the following equation, ${ }^{9,24}$

$$
V_{\mathrm{g}}=\frac{t_{\mathrm{R}} F}{w} \cdot \frac{3}{2} \cdot \frac{\left(P_{\mathrm{i}} / P_{\mathrm{o}}\right)^{2}-1}{\left(P_{\mathrm{i}} / P_{\mathrm{o}}\right)^{3}-1}
$$

where $F$ is the flow rate of the carrier gas at N.T.P. $\left(\mathrm{ml} \mathrm{min}{ }^{-1}\right)$ measured with a soap-film flow-meter, $w$ is a polymer loading weight $(\mathrm{g}), P_{\mathrm{i}}$ and $P_{\mathrm{o}}$ are the column inlet and outlet pressures, respectively. For each column measurements were carried out by raising the column temperature $T(\mathrm{~K})$ from 318 to $423 \mathrm{~K}$, whereas cooling-down measurements were specially carried out on columns No. 9 and 14. By plotting $\log V_{\mathrm{g}}$ vs. $10^{3} / T$, the retention diagrams were obtained.

\section{Scanning Electron Microscopy}

Scanning electron microscope (SEM) photo- graphs were obtained on a Hitachi-Akashi MSM4C-102. The polymer was cast onto a silanetreated glass plate from a chloroform solution and coated with $200 \mathrm{~A}$ of gold. The samples were observed over a magnification range of 2000 to $5000 \mathrm{X}$ by varying the beam angles from $0^{\circ}$ to $45^{\circ}$. The SEM was operated at $30 \mathrm{kV}$ and no significant beam damage of the polymer films occurred under this condition.

\section{RESULTS AND DISCUSSION}

IGC Measurement-Heating-Up and Cooling-Down

As shown in Figure 1, the retention diagram for the heating-up measurement on the physical blend of PEO with PS (No. 9, $50 \mathrm{wt} \%$ PEO) shows two distinct upward deviations from the straight line portions of the $\log V_{\mathrm{g}}$ vs. $1 / T$ diagram. The one around $60^{\circ} \mathrm{C}$ is attributed to the melt-transition of $\mathrm{PEO}$ and the other around $95^{\circ} \mathrm{C}$ corresponds to be glass-transition of PS. Thus, PEO and PS are not miscible with each other, and phase separation occurs on mixing. In the cooling-down diagram, the freeze-transition of PEO can be observed to some extent around $50^{\circ} \mathrm{C}$ (about $10^{\circ} \mathrm{C}$ lower than in the heating-up measurement). This lag may be due to

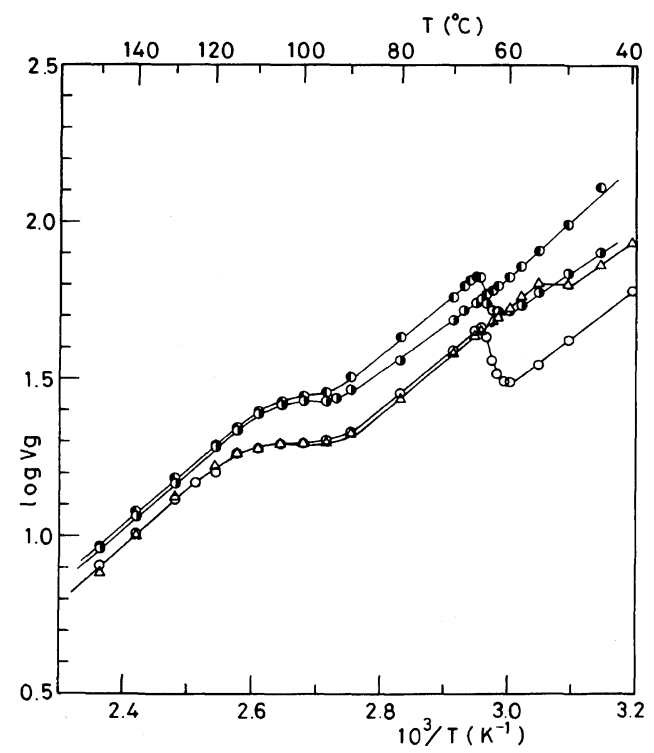

Figure 1. Retention diagrams for n-octane on PEO/PS: (O) No. 9 (heating-up); $(\triangle)$ No. 9 (coolingdown); (囚) No. 17 (PS: upper layer); (囚) No. 18 (PEO: upper layer). 
the fast cooling rate $\left(0.1 \mathrm{~K} \mathrm{~min}^{-1}\right)$ compared with the time required for crystallization of PEO. In the successive heating-up measurement, the melttransition of PEO was clearly observed around $60^{\circ} \mathrm{C}$ as in the first heating-up measurement.

\section{The Influence of Loading of PEO on Retention Diagram}

The retention diagrams for the columns No. 13, 14,15 , and 16, where only PEO was loaded onto the support, are shown in Figure 2. In the cooling-down diagram, the freeze-transition is slightly observed around $50^{\circ} \mathrm{C}$ as in Figure 1. Since the thermal behaviour of PEO has been extensively investigated by other workers, ${ }^{25-27}$ the following discussion is restricted to the first heating-up measurements.

As can be seen from Figure 2, the changes in $\log V_{\mathrm{g}}$ before and after melt-transition of PEO (the depth of the Z-shaped diagram) are nearly proportional to the amount of PEO loaded onto the support in the range from 5 to $20 \%$. Thus, the difference in the depth of the Z-shaped diagrams in this range is attributed to the thickness of the PEO layer covering the support.

Figure 3 shows the dependence of $\log V_{\mathrm{N}}\left(V_{\mathrm{N}}\right.$ : net retention volume) on $1 / T$ for the columns No. 1216 . When the loadings are above $5 \%$, the retention

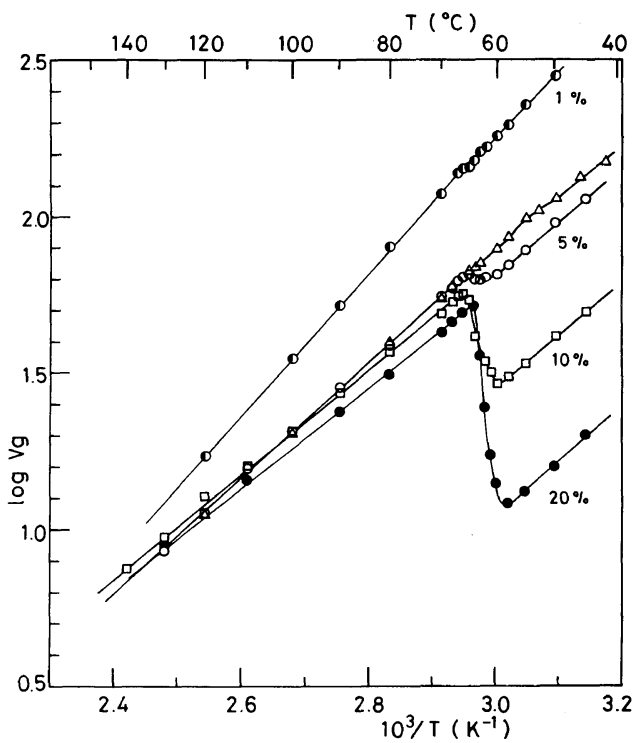

Figure 2. Effect of loading of PEO on retention diagram: (๑) No. 13; $(\triangle)$ No. 14 (cooling-down); ( No. 14 (heating-up); ( $\square$ ) No. 15; (○) No. 16. diagrams below $T_{\mathrm{m}}$ almost overlap with each other, while the retention diagram for the $1 \%$ loading comes close to that for the $0 \%$ loading. The reason for this behavior may be the contribution of surface adsorption and bulk sorption of solute onto polymer. ${ }^{28,29}$ In this study, we loaded the polymer onto the support about $10 \%$ to avoid the problems that arise at loadings lower than $5 \%$.* $^{*}$

\section{The Surface Topography of the Physical Blend of $P E O$ with $P S$}

Thomas and O'Malley showed that the surface topography of the physical blend of PEO with PS is

* Above $5 \%$, the amount of surface adsorption is almost constant and bulk sorption is negligible, i.e., the crystallinity of PEO is nearly one. Below $5 \%$, the adsorption contribution at the polymer-support interface or at the surface of support uncovered by polymer should be taken into consideration.

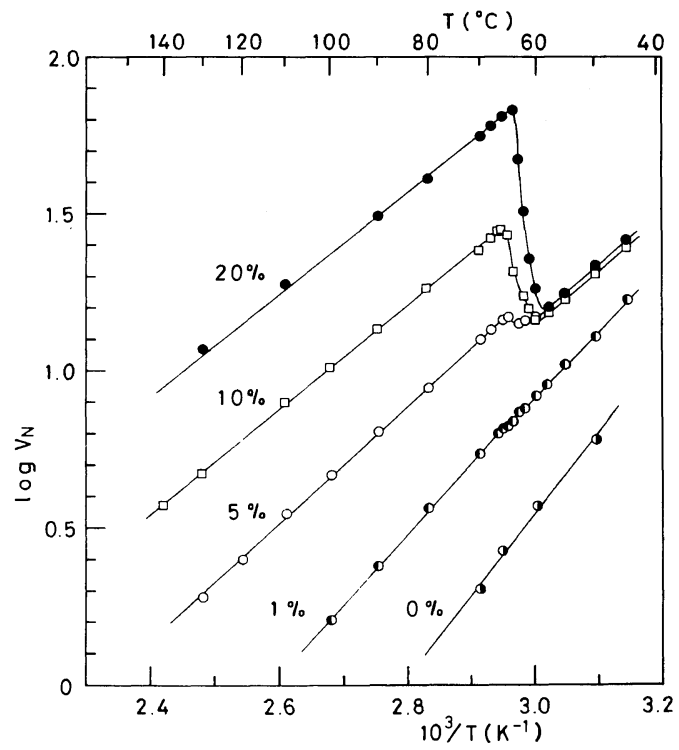

Figure 3. Effect of loading of $\mathrm{PEO}$ on the $\log V_{\mathrm{N}} v s$.

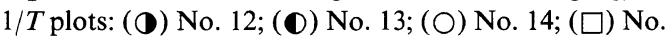
15, (O) No. 16.

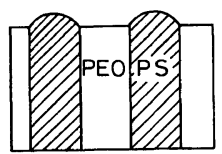

Figure 4. A model for the surface topography of the physical blend of PEO with PS presented by Thomas and O'Malley. ${ }^{21}$ 
representable not by a classic continuous overlayer model but by a nonplanar alternative discontinuous one as shown in Figure $4 .^{21}$ The retention diagrams for the overlayer-loading columns (No. 17 and 18) are depicted in Figure 1. Although the composition of PEO and PS in each of these two columns is almost the same as that in column No. $9(\mathrm{ca} .50 \mathrm{wt} \%$ PEO), the retention diagrams for these three columns differ from one another. Therefore, the surface structure of the physical blend of PEO with PS deposited onto Chromosorb is considered not to be composed of double layers.

\section{SEM Photographs of Physical Blends of PEO with $P S$}

The SEM photographs of cast films of polymer blends prepared under various compositions are given in Figure 5. In photograph (a) ( $80 \mathrm{wt} \% \mathrm{PEO})$, a sea-island phase separation can clearly be observed. An increase in the area of the island phase is observed in photograph (b) (50 wt $\%$ PEO). Consequently, in photographs (a) and (b), the sea and island phases are regarded as the PEO and PS domains, respectively. In photograph (c) (44 wt \% PEO), the inversion of sea-island phase is observed, i.e., the PEO and PS domains form the island and sea phases, respectively. Furthermore, the PS domain was also found as a smaller island phase in the PEO domain. As shown in photograph (d) (33 $w t \%$ PEO), it is characteristic that the area of the island phase of the PEO domain is smaller than that in photograph (c) and that the fine island phase of the PS domain in the PEO domain appears to vanish. The polymer surface shown in photograph (d) looks relatively smooth in comparison with those observed in photographs (a), (b) and (c). In the polymer surface of $20 \mathrm{wt} \%$ PEO, the phase separation cannot be observed at all.** Thus, the PEO domain must be completely covered by the PS domain below $20 \mathrm{wt} \%$ PEO. These morphological changes in the polymer surface may possibly be due to the difference in the relative intensity of surface tension between PEO and PS.

The SEM photographs of polymer blends measured at a beam angle of $45^{\circ}$ are shown in Figure 6. It can clearly be seen from the shining or shaded part that the surface of the polymer blend is not planar

** According to the SEM observation of the polymer blend of $20 \mathrm{wt} \%$ PEO, the polymer surface was homogeneous and completely flat even at a magnification of $15000 \times$.
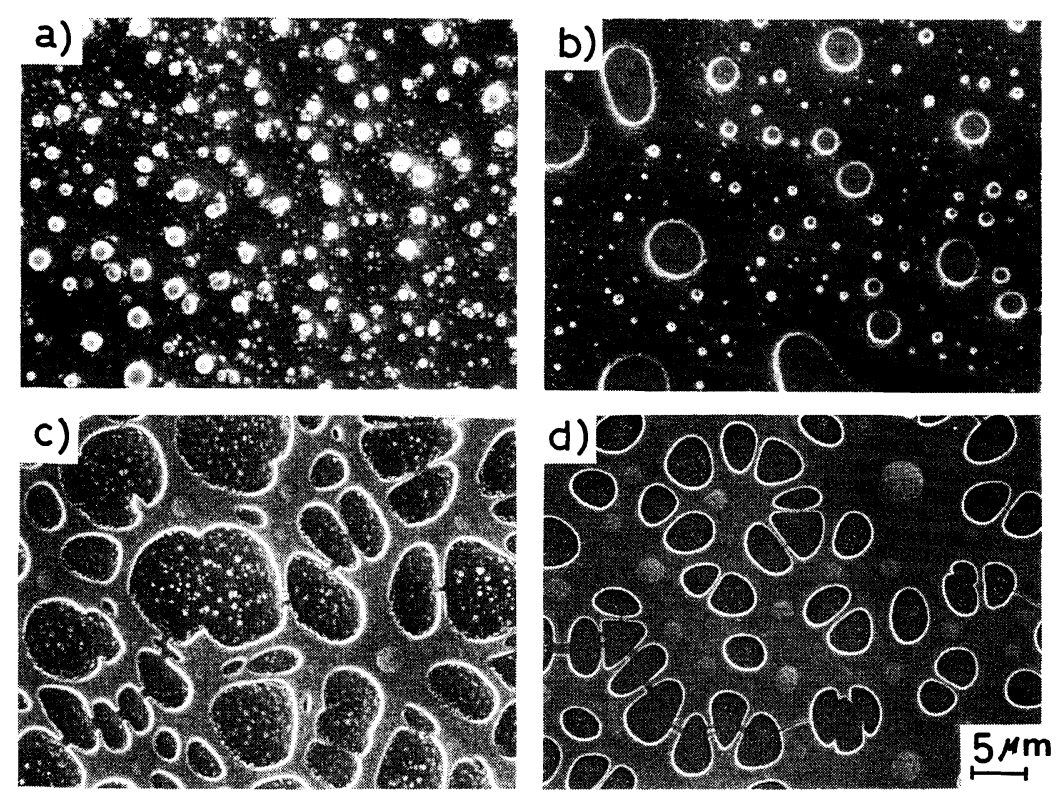

Figure 5. SEM photographs of the physical blends of PEO with PS cast from chloroform: wt $\%$ $\mathrm{PEO}=$ (a) 80, (b) 50, (c) 44, and (d) 33. 

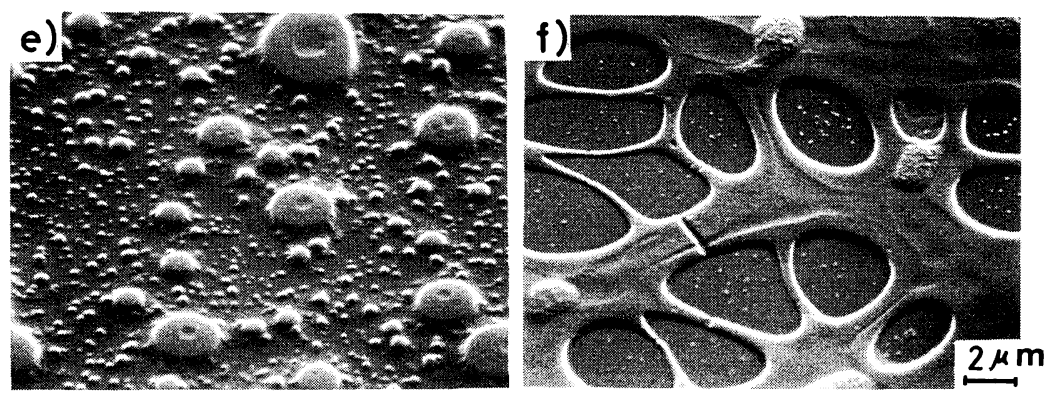

Figure 6. SEM photographs of the physical blends of PEO with PS cast from chloroform: beam angle $=45^{\circ} ; \mathrm{wt} \% \mathrm{PEO}=$ (e) 50 and (f) 33.

and that the surface of the PS domain always protrudes above the PEO domain. This surface topography of the polymer blend agrees with the surface model presented by Thomas and O'Malley as shown in Figure 4, except for the domain sizes. ${ }^{21}$

\section{The Influence of the PEO/PS Composition on Retention Diagram}

In Figure 7 are shown the retention diagrams for the columns prepared at various compositions. The retention diagram for column No. 6 (39 $\mathrm{wt} \%$ PEO) was exactly the same as that for column No. 7 (44 $\mathrm{wt} \% \mathrm{PEO}$ ). In general, the $\mathrm{Z}$-shapedness around the transition of a polymer increases with loading onto the support. ${ }^{22,24}$ As shown in Figure 7, the Zshaped curves around the $T_{\mathrm{g}}$ of PS undergo little change. In contrast, the great change in them occurs around the $T_{\mathrm{m}}$ of PEO with only a slight change in composition. In the range of 10 to $20 \mathrm{wt} \% \mathrm{PEO}$, the straight line slope changes at the $T_{\mathrm{m}}$ of PEO but no clear Z-shaped curve is observed, which implies that the PEO domain is nearly covered with the PS layer and the $n$-octane cannot interact with PEO at the polymer surface. A clear Z-shaped curve can be observed from $33 \mathrm{wt} \%$ PEO and its depth increases gradually up to $44 \mathrm{wt} \%$ PEO. The depth of the Zshaped curve increases drastically from 44 to 50 $\mathrm{wt} \%$ PEO. In the range of PEO content above 50 $\mathrm{wt} \% \mathrm{PEO}$, however, further increase is hardly observable. To determine whether this change in the retention diagrams is attributable to composition or the amount of PEO in a column ( $\left.w_{\text {PEO }}\right)$, measurements were made on columns No. 5 and 11 and the results are shown in Figure 8. The composition in both columns is the same ( $33 \mathrm{wt} \%$ ), but the values of $w_{\mathrm{PEO}}$ are different. The difference in the retention diagrams for the two columns is much smaller than

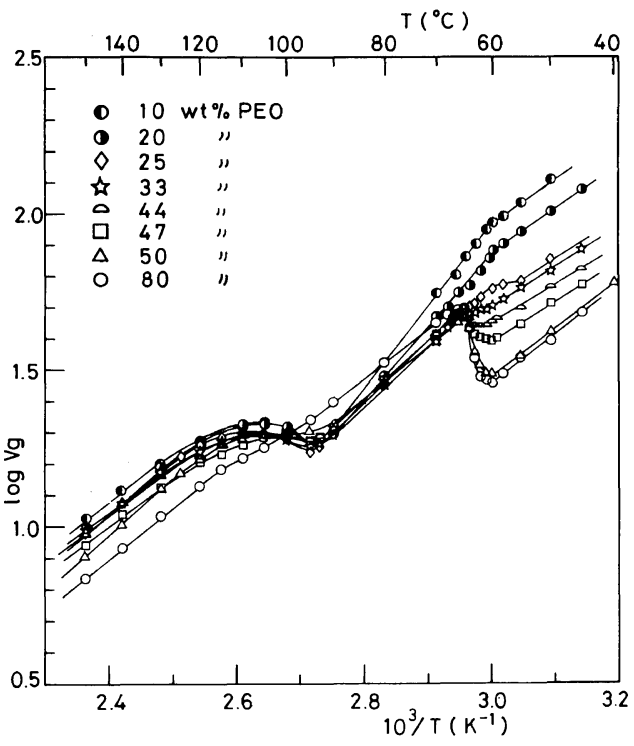

Figure 7. Effect of composition on retention diagram for $n$-octane on the physical blends of PEO with PS: (D)

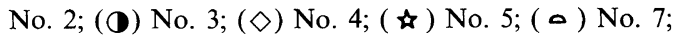
$(\square)$ No. 8; $(\triangle)$ No. 9; (○) No. 10.

that for columns No. $11\left(w_{\mathrm{PEO}}=0.230 \mathrm{~g}, 33 \mathrm{wt} \%\right.$ PEO) and No. $9\left(w_{\mathrm{PEO}}=0.210 \mathrm{~g}, 50 \mathrm{wt} \%\right.$ PEO $)$. Therefore, we may consider that the morphologies at the polymer surface in the columns prepared at the same composition are almost the same, regardless of the polymer loading. This definitely indicates that the change in the retention diagrams as shown in Figure 7 is due to difference in composition.

From these results of IGC and SEM, we can conclude that the following four morphological states exist in physical blends of PEO with PS: (1) the PEO domain is almost covered with the PS layer at loadings lower than $20-25 \mathrm{wt} \%$ PEO; (2) the 


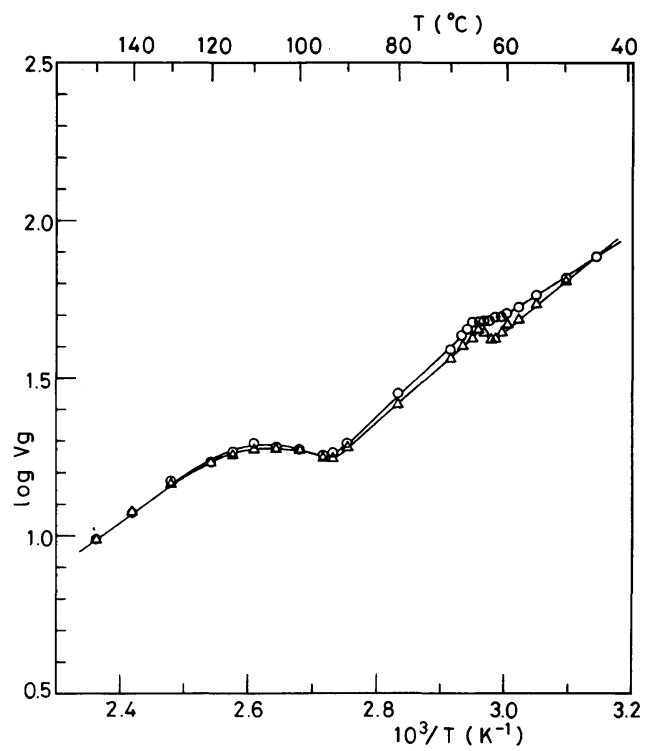

Figure 8. Retention diagrams for $n$-octane on the columns prepared at $33 \mathrm{wt} \%$ PEO: (O) No. 5 (polymer: 9.5 wt $\%$ ); $(\triangle)$ No. 11 (polymer, $13.2 \mathrm{wt} \%$ ).

PEO domain appears at the polymer surface at a PEO content between 25 and $33 \mathrm{wt} \%$ and its surface area increases gradually with increasing PEO content; (3) the morphology of these two polymer systems drastically changes from 44 to $50 \mathrm{wt} \% \mathrm{PEO}$; (4) no essential morphological change occurs above $50 \mathrm{wt} \%$ PEO. It should be noted that the polymer films investigated by IGC were cast onto Chromosorb and those investigated by SEM were cast onto glass plates.

\section{Temperature Dependence of $V_{\mathrm{g}}$-Composition Relationship}

Figure 9 shows the influence of composition on $V_{\mathrm{g}}$ at various temperatures. It was reported that the blends of high molecular weights PS with $\operatorname{poly}(n-$ butyl methacrylate) were incompatible and the plots of $V_{\mathrm{g}} v s . \mathrm{wt} \% \mathrm{PS}$ at $140^{\circ} \mathrm{C}$ for several solutes were linear. ${ }^{10}$ In the plots at a column temperature of $50^{\circ} \mathrm{C}$, at which PEO does not yet melt, we can observe changes in the slope of the line at 25 and 50 $\mathrm{wt} \%$ PEO. These changes in the slope correspond to the changes in the retention mechanism of $n$-octane on the surface of polymer blend. The fundamental surface structure of the polymer blend greatly changes at these compositions. These changes in the plots at $50^{\circ} \mathrm{C}$ are in good agreement with the

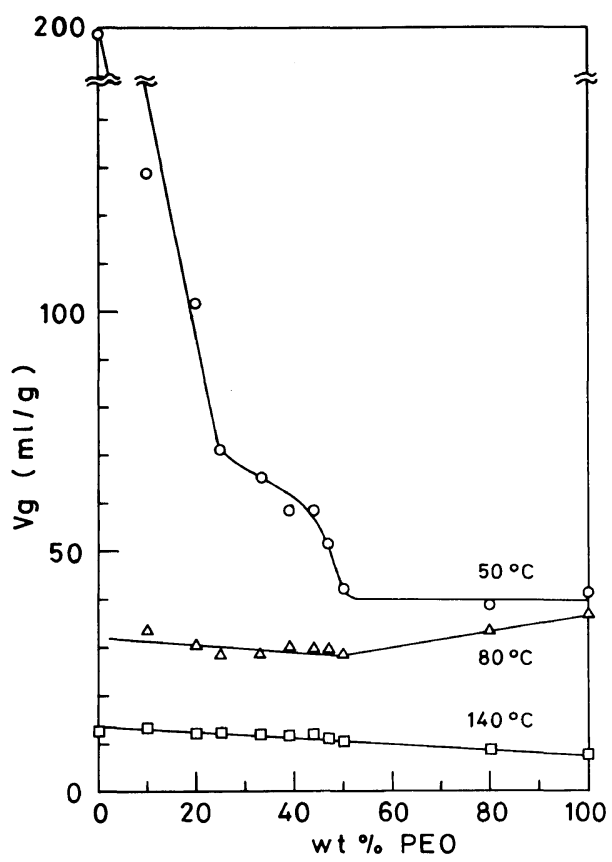

Figure 9. Effect of composition on $V_{\mathrm{g}}$ in physical blends of PEO with PS at various temperatures.

morphological changes described above. By extrapolating the plot of $V_{\mathrm{g}}$ at $50^{\circ} \mathrm{C}$ to 0 or $100 \mathrm{wt} \%$ PEO, we can estimate the $V_{\mathrm{g}}$ on the column with only PS or PEO loaded. The intercepts at 0 and 100 $\mathrm{wt} \%$ PEO were in good agreement with the $V_{\mathrm{g}}$ values obtained by independent measurements (columns No. 1 and 15). This indicates that the surface structure of the polymer blend changes continuously around 0 and $100 \mathrm{wt} \%$ PEO. In the plots at $80^{\circ} \mathrm{C}$, above the $T_{\mathrm{m}}$ of PEO and below the $T_{\mathrm{g}}$ of PS, the slope of the straight line changes slightly at $50 \mathrm{wt} \%$ PEO. In the plots at $140^{\circ} \mathrm{C}$, above the $T_{\mathrm{g}}$ of PS, the slope of the straight line is constant regardless of composition. These results suggest that the surface of the polymer blend is in a "semi-melted" state at $80^{\circ} \mathrm{C}$ and a "fully-melted" state at $140^{\circ} \mathrm{C}$.

\section{The Effect of Addition of PEGNPE}

In Figure 10 are shown the retention diagrams for the column No. 9 (50 $\mathrm{wt} \%$ PEO) and the column No. 19 prepared by the $0.4 \mathrm{wt} \%$ addition of PEGNPE at the composition of $50 \mathrm{wt} \%$ PEO. Comparing Figures 10 with 7, we find that the depth of the Z-shaped diagram around the $T_{\mathrm{m}}$ of PEO observed on column No. 19 is smaller than that 


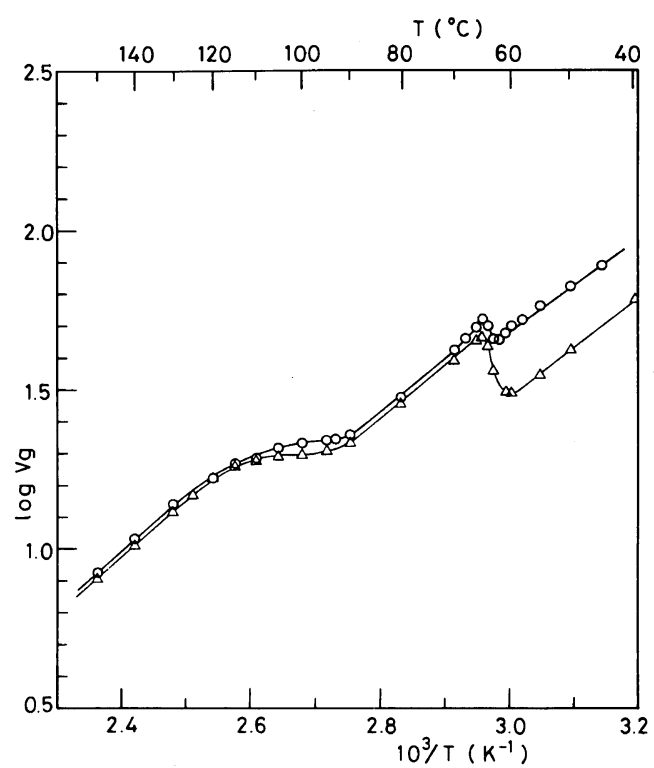

Figure 10. Retention diagrams for $n$-octane on the columns prepared at $50 \mathrm{wt} \%$ PEO: $(\triangle)$ No. 9; (O) No. 19 (PEGNPE was added).

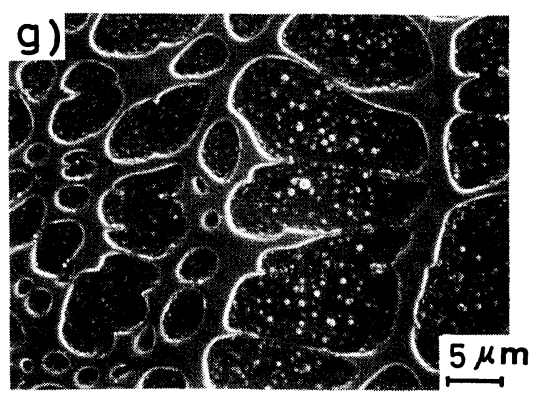

Figure 11. SEM photograph of the physical blend of PEO with PS cast from chloroform: wt $\% \mathrm{PEO}=50$, PEGNPE was added.

observed on column No. 9 (50 $\mathrm{wt} \%$ PEO) and is almost the same as that observed on column No. 7 (44 $\mathrm{wt} \%$ PEO). Consequently, it can be assumed that by the addition of PEGNPE to the physical blend of PEO with PS these incompatible polymers mix to a certain extent. This implies that PEGNPE acts as a surfactant in this polymer blend system.

The SEM photograph of the film prepared at 50 $\mathrm{wt} \%$ PEO by the addition of PEGNPE is given in Figure 11. Comparing Figures 11 and 5, we can see that the surface structure of this film is different from that prepared at $50 \mathrm{wt} \%$ PEO [photograph (b)] but is similar to that prepared at $44 \mathrm{wt} \%$ PEO [photograph (c)]. Thus, the boundary area is a little diminished by the addition of PEGNPE. This observation is consistent with the change in the Zshaped diagram observed on IGC.

\section{REFERENCES}

1. O. Smidsrød and J. E. Guillet, Macromolecules, 2 272 (1969).

2. A. Lavoie and J. E. Guillet, Macromolecules, 2, 443 (1969).

3. J. E. Guillet and A. N. Stein, Macromolecules, 3, 102 (1970).

4. J.-M. Braun, A. Lavoie, and J. E. Guillet, Macromolecules, 8, 311 (1975).

5. J.-M. Braun and J. E. Guillet, Adv. Polym. Sci., 21, 107 (1976).

6. K. Ito, H. Sakakura, and Y. Yamashita, J. Polym. Sci., Polym. Lett. Ed., 15, 755 (1977).

7. K. Ito, H. Sakakura, K. Isogai, and Y. Yamashita, $J$. Polym. Sci., Polym. Lett. Ed., 16, 21 (1978).

8. M. Galin and M. C. Rupprecht, Macromolecules, 12, 506 (1979).

9. K. Ito, N. Usami, and Y. Yamashita, Macromolecules, 13, 216 (1980).

10. G. DiPaola-Baranyi, Polym. Prepr., Am. Chem. Soc., Div. Polym. Chem., 21(2), 214 (1980).

11. T. Suzuki, Y. Murakami, Y. Tsuji, and Y. Takegami, J. Polym. Sci., Polym. Lett. Ed., 14, 675 (1976).

12. T. Suzuki, Y. Murakami, and Y. Takegami, $J$. Polym. Sci., Polym. Lett. Ed., 17, 241 (1979).

13. T. Suzuki, Y. Murakami, and Y. Takegami, Polym. J., 12, 183 (1980).

14. J. M. Short and R. G. Crystal, Appl. Polym. Symp., 16, 137 (1971).

15. M. Gervais and B. Gallot, Markomol. Chem., 171, 157 (1973).

16. M. Gervais and B. Gallot, Makromol. Chem., 174, 193 (1973).

17. K. Nakamura, R. Endo, and M. Takeda, J. Polym. Sci., Polym. Phys. Ed., 14, 135 (1976).

18. K. Nakamura, R. Endo, and M. Takeda, J. Polym. Sci., Polym. Phys. Ed., 14, 1287 (1976).

19. H. R. Thomas and J. J. O'Malley, Macromolecules, 12, 323 (1979).

20. J. J. O'Malley, H. R. Thomas, and G. M. Lee, Macromolecules, 12, 996 (1976).

21. H. R. Thomas and J. J. O'Malley, Polym. Prepr., Am. Chem. Soc., Div. Polym. Chem., 21(1), 144 (1980).

22. T. Inui, Y. Murakami, T. Suzuki, and Y. Takegami, to be published.

23. D. G. Gray and J. E. Guillet, Macromolecules, 5, 316 (1972).

24. J.-M. Braun and J. E. Guillet, Macromolecules, 8, 


\section{Morphological study of PEO-PS}

882 (1975).

25. P. C. Ashman and C. Booth, Polymer, 13, 459 (1972).

26. E. Alfthan and A. de Ruvo, Polymer, 16, 692 (1975).

27. Y. Kambe, Polymer, 21, 352 (1980).
28. G. Courval and D. G. Gray, Macromolecules, 8, 326 (1975).

29. Yu, S. Lipatov and A. E. Nesterov, Macromolecules, 8, 889 (1975). 